\title{
SỰ PHỔ BIẾN CỦA ACESULFAME K TRONG ĐỒ UỐNG KHÔNG CỒN ĐANG ĐƯợC KINH DOANH TẠI BİNH DƯƠNG NĂM 2018 VÀ TUÂN THỦ VỀ KHÄI BÁO ACESULFAME K TRÊN NHĀN CỦA DOANH NGHIỆP
}

Nguyễn Văn Đạt, Trần Minh Hoàng*, Nguyễn Thị Thanh Tuyền, Nguyễn Thanh Trúc

Chi cục An toàn vệ sinh thục phẩm Bình Dương

(Ngày đến tòa soạn: 8/7/2019; Ngày sủa bài sau phản biện: 12/9/2019;

Ngày chấp nhận đăng:20/9/2019)

\section{Tóm tắt}

Đặt vấn đề: Acesulfame-K (ACK) là một trong những chất làm ngọt nhân tạo có hàm lượng calo thấp trong chế độ ăn hiện đại, mặc dù dữ liệu độc tính của nó được báo cáo cho đến nay được coi là không đầy đủ. Việc lạm dụng ACK trong sản xuất thực phẩm được coi là vấn đề ảnh hưởng lâu dài đến sức khỏe người tiêu dùng.

Mục tiêu: Xác định tỷ lệ sử dụng, hàm lượng ACK trong đồ uống không cồn đang kinh doanh trên địa bàn tỉnh Bình Dương và tỷ lệ tuân thủ về khai báo $\mathrm{ACK}$ trên nhãn sản phẩm của doanh nghiệp.

Phương pháp nghiên cứu: Nghiên cứu mô tả cắt ngang thực hiện trên toàn bộ 58 mẫu đồ uống không cồn mang thương hiệu khác nhau từ tháng 7 đến tháng 10 năm 2018 đang kinh doanh trên địa bàn tỉnh Bình Dương.

Kết quả: Có $50 \%$ các sản phẩm đồ uống có đường đang kinh doanh tại tỉnh Bình Dương có chứa $\mathrm{ACK}$ trong sản phẩm. Hàm lượng $\mathrm{ACK}$ trung bình là 175,2 $\pm 113,4 \mathrm{mg} / \mathrm{L}$, cao nhất là 481,7 $\mathrm{mg} / \mathrm{L}$, thấp nhất là $11,85 \mathrm{mg} / \mathrm{L}$; hàm lượng $\mathrm{ACK}$ trung bình cao nhất trong nhóm sản phầm đồ uống hương liệu $(208,2 \pm 127,9)$; thấp nhất trong nhóm nước trái cây $(99 \pm 92,8)$. Có $65,5 \%$ sản phẩm có sử dụng $\mathrm{ACK}$ trong thành phần của sản phẩm nhưng không khai báo trên nhãn cho người tiêu dùng và cơ quan quản lý được biết, do đó cần tăng cường công tác kiểm tra, giám sát các sản phẩm đồ uống có đường và xử lý nghiêm đối với những doanh nghiệp có sử dụng $\mathrm{ACK}$ nhưng không khai báo trên nhãn.

Tù̀ khóa: Acesulfame K, đồ uống không cồn, ghi nhãn, Bình Dưong.

\section{1. ĐẠT VẤN ĐỀ}

Một số nghiên cứu dịch tễ học đã chỉ ra rằng chất làm ngọt nhân tạo có lợi cho giảm cân và cho những người không dung nạp glucose và đái tháo đường type 2 [5]. Tuy nhiên, bằng chứng tích lũy trong những năm gần đây cho thấy việc sử dụng chất làm ngọt nhân tạo có thể gây rối loạn trao đổi chất của con người, đặc biệt là sự điều hòa glucose. Chất tạo ngọt nhân tạo đã được tìm thấy gây ra không dung nạp glucose và gây ra hội chứng chuyển hóa và cũng liên quan đến tăng cân cơ thể cao hơn. Những phát hiện này cho thấy rằng chất làm ngọt nhân tạo có thể làm tăng nguy cơ béo phì [5]. Hiện nay, 5 chất làm ngọt nhân tạo không dinh dưỡng phổ biến được Cục quản lý Thực phẩm và Dược phẩm Hoa Kỳ (FDA) chấp thuận là: acesulfame kali (ACK), sucralose, aspartame, saccharin và neotame. Trong số đó, ACK, được phát hiện vào năm 1967, ngọt hơn đường gấp khoảng 200 lần. $\mathrm{ACK}$ đã được phê duyệt để sử dụng trong một loạt các sản phẩm thực phẩm bao gồm đồ uống có ga, sản phẩm làm bánh, thức ăn trẻ em và thực phẩm đông lạnh [6]. ACK là một trong những chất 
làm ngọt nhân tạo có hàm lượng calo thấp trong chế độ ăn hiện đại. Mặc dù dữ liệu độc tính của nó được báo cáo cho đến nay được coi là không đầy đủ, các nghiên cứu trước đây đã phát hiện ra rằng $\mathrm{ACK}$ có độc tính với gen và có thể ức chế sự lên men glucose do vi khuẩn đường ruột. Ngoài ra, $\mathrm{ACK}$, như natri saccharin và natri cyclamate, thuộc về sulfonamides, một lớp hóa học liên quan đến hoạt tính kháng khuẩn [5].

ACK được sử dụng làm phụ gia thực phẩm ở hơn 100 quốc gia do tính ổn định cao trong điều kiện có tính acid và nhiệt độ. Tại Việt Nam, quy định việc sử dụng $\mathrm{ACK}$ được quy định rõ ràng. Cụ thể, mức sử dụng ACK trong thực phẩm dao động từ $200-1.000 \mathrm{mg} / \mathrm{kg}$ [1]. Bên cạnh quy định giới hạn sử dụng của $\mathrm{ACK}$ trong thực phẩm, thì phải khai báo $\mathrm{ACK}$ trên nhãn sản phẩm trong trường hợp có sử dụng trong sản xuất thực phẩm [2].

Qua hồi cứu y văn, các nghiên cứu về sử dụng $\mathrm{ACK}$ trong thực phẩm tại Việt Nam vẫn còn hạn chế. Nghiên cứu này nhằm xác định hàm lượng $\mathrm{ACK}$ và khai báo sử dụng $\mathrm{ACK}$ trong đồ uống có đường được kinh doanh trên địa bàn tỉnh Bình Dương. Kết quả của nghiên cứu sẽ cung cấp số liệu cụ thể để cơ quan chức năng thực hiện tốt công tác giám sát thực phẩm, có biện pháp xử lý phù hợp với những doanh nghiệp không tuân thủ quy định của pháp luật về sử dụng ACK trong sản xuất thực phẩm, góp phần bảo vệ sức khỏe người tiêu dùng.

\section{MỤC TIÊU NGHIÊN CÚU}

- Xác định tỷ lệ sử dụng ACK trong một số loại đồ uống có đường đang kinh doanh trên địa bàn tỉnh Bình Dương năm 2018.

- Xác định hàm lượng ACK trung bình trong một số loại đồ uống có đường đang kinh doanh trên địa bàn tỉnh Bình Dương năm 2018.

- Xác định tỷ lệ các doanh nghiệp tuân thủ quy định về sử dụng ACK (khai báo, hàm lượng) trong một số loại đồ uống có đường đang kinh doanh trên địa bàn tỉnh Bình Dương năm 2018.

\section{PHƯỚNG PHÁP NGHIÊN CÚU}

Nghiên cứu mô tả cắt ngang thực hiện trên toàn bộ 58 mẫu đồ uống không cồn mang thương hiệu khác nhau từ tháng 7 đến tháng 10 năm 2018. Mẫu được chọn theo phương pháp ngẫu nhiên đơn theo từng lô sản phẩm, mẫu loại ra là những mẫu có cùng thương hiệu đã được chọn, dựa vào nhãn sản phẩm để tránh trùng mẫu, mỗi mẫu được chọn một lần với thể tích là $500 \mathrm{~mL} / \mathrm{mẫu}$. Mẫu được niêm phong và dán mã hóa để tránh trùng kết quả. Sau đó được đưa về phòng xét nghiệm để định lượng hàm lượng $\mathrm{ACK}$. Hàm lượng $\mathrm{ACK}$ được định lượng bằng phương pháp WRT/TM/CH/03.10 (LC/UV) của phòng kiểm nghiệm đạt chuẩn ISO 17025. Sử dụng phần mềm EPIDATA 3.1 để nhập liệu và STATA 13.1 để xử lý số liệu.

\section{KẾT QUẢ}

\section{1. Đặc tính nền}

Bảng 1. Đặc tính nền của đồ uống không cồn trong nghiên cứu ( $n=58)$

\begin{tabular}{|l|c|c|}
\hline \multicolumn{1}{|c|}{ Đặc điểm } & Tần số (n) & Tỉ lệ (\%) \\
\hline Đồ uống có ga & 23 & 39,7 \\
\hline Nước trái cây & 16 & 27,6 \\
\hline Trà, cà phê, cacao & 12 & 20,7 \\
\hline Nước tăng lực & 8 & 13,8 \\
\hline Đồ uống hương liệu & 17 & 29,3 \\
\hline Khác & 5 & 8,6 \\
\hline Sản xuất trong nước & 52 & 89,7 \\
\hline
\end{tabular}


Khảo sát 58 mẫu đồ uống không cồn thuộc 18 doanh nghiệp, có khoảng gần $40 \%$ mẫu đồ uống được khảo sát có chứa ga. Nhóm đồ uống hương liệu chiếm tỷ lệ cao nhất (29,3\%); nhóm đồ uống nước trái cây và trà, cà phê, ca cao chiếm tỷ lệ lần lượt là $27,6 \%$ và $20,7 \%$. Có $89,7 \%$ đồ uống được sản xuất trong nước.

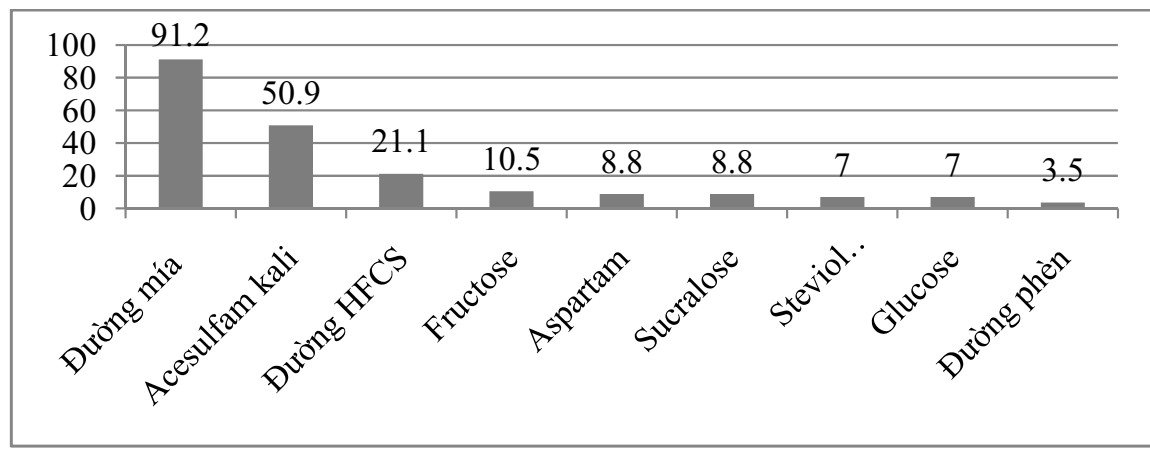

Hình 1. Đặc điểm sử dụng chất tạo ngọt trong đồ không cồn trong nghiên cứu ( $n=57)$

Có $57 / 58$ sản phẩm khai báo có sử dụng chất tạo ngọt trong thành phần sản phẩm, trong đó: đường mía được sử dụng nhiều nhất $(91,2 \%)$, tiếp theo là Acesulfam kali $(50,9 \%)$, các lại chất tạo ngọt khác chiếm tỷ lệ từ 3,5 đến $21 \%$.

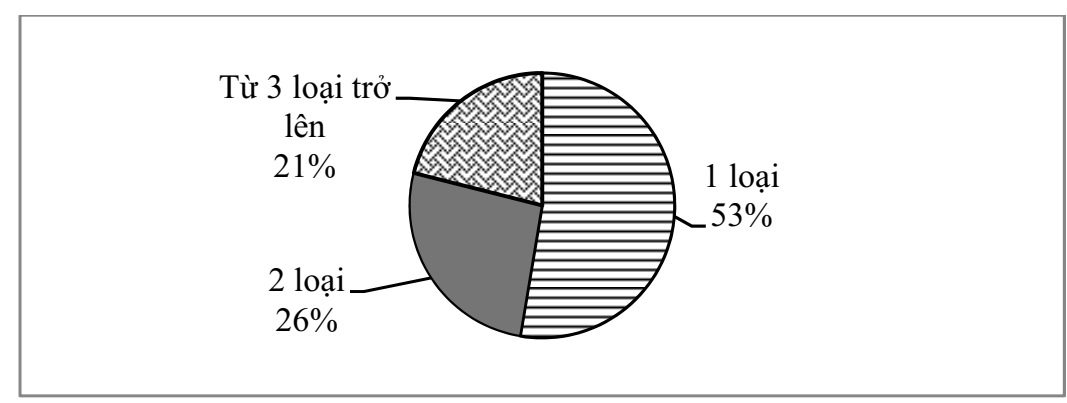

Hình 2. Số lương chất làm ngọt trong sản phẩm

Có trên $45 \%$ các sản phẩm sử dụng từ 2 chất làm ngọt trở lên trong sản phẩm nước giải khát không cồn.

\section{2. Đặc điểm sử dụng Acesulfame $\mathrm{K}$ trong đồ uống không cồn}

Bảng 2. Hàm luợngAcesulfame K theo nhóm đồ uống $(n=29)$

\begin{tabular}{|l|c|c|}
\hline Hàm lựng Acesulfame $\boldsymbol{K}$ & Nhỏ $\boldsymbol{n h a ̂ ́ t ~}-$ lớn nhất $(\boldsymbol{m g} / \boldsymbol{l})$ & $\boldsymbol{T B} \pm \boldsymbol{D L C}($ *) \\
\hline Nước trái cây & $(11,9-296,4)$ & $99 \pm 92,8$ \\
\hline Trà, cà phê, cacao & 00 & 00 \\
\hline Nước tăng lực & $(115-208,3)$ & $152,4 \pm 32,4$ \\
\hline Đồ uống hương liệu & $(47,72-481,7)$ & $208,2 \pm 127,9$ \\
\hline Tổng & $(11,9-481,7)$ & $175,2 \pm 113,4$ \\
\hline
\end{tabular}

(*) Trung bình \pm Độ lệch chuẩn

Có $50 \%$ các sản phẩm đồ uống có chứa $\mathrm{ACK}$ trong sản phẩm. Hàm lượng $\mathrm{ACK}$ trung bình là $175,23 \pm 113,35 \mathrm{mg} / \mathrm{L}$, cao nhất là $481,7 \mathrm{mg} / \mathrm{L}$, thấp nhất là $11,85 \mathrm{mg} / \mathrm{L}$; Hàm lượng $\mathrm{ACK}$ trung bình cao nhất trong nhóm sản phầm đồ uống hương liệu $(208,2 \pm 127,9)$; thấp nhất trong nhóm nước trái cây $(99,03 \pm 92,8)$. Đối chiếu với hàm lượng ACK theo quy định thì các sản phẩm đều đạt (29/29 sản phẩm xét nghiệm có chứa $\mathrm{ACK})$. 


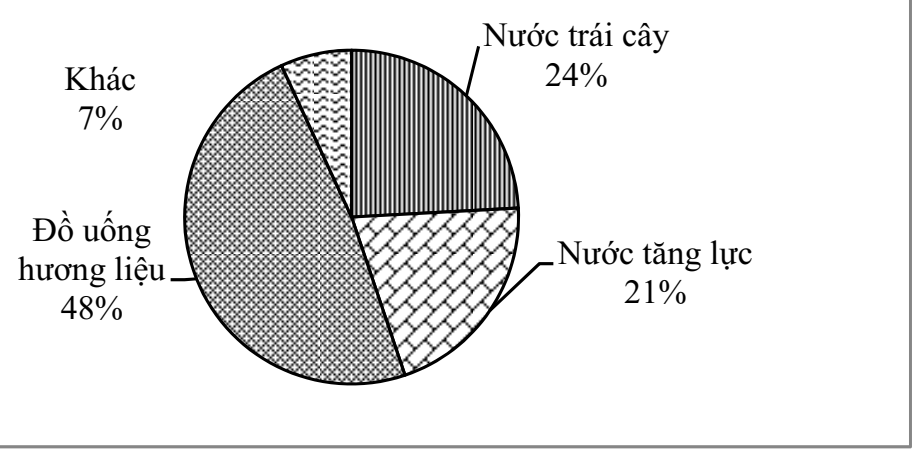

Hình 3. Tỷ lệ sư dụng Acesulfame K theo nhóm đồ uống $(n=29)$

Trong số 29 sản phẩm xét nghiệm có chứa ACK, thì nhóm đồ uống hương liệu chứa ACK nhiều nhất (48,3\%); nhóm trà, cà phê, ca cao không chứa $\mathrm{ACK}$.

Bảng 2. Tỷ lệ đồ uống có khai báo sủ dụng ACK trên nhãn đối với nhũ̃ng sản phẩm xét nghiệm có chưa $A C K(n=29)$

\begin{tabular}{|l|c|c|}
\hline \multicolumn{1}{|c|}{ Đặc điểm } & Tần số (n) & Tỉ lệ (\%) \\
\hline Xét nghiệm có $A C K(n=58)$ & 29 & 50 \\
\hline Khai báo sủ dụng ACK trên nhãn $(n=29)$ & 10 & 34,5 \\
\hline
\end{tabular}

Mặc dù xét nghiệm có chứa ACK trong sản phẩm, tuy nhiên chỉ có 10 trong số 29 sản phẩm có khai báo sử dụng ACK trên nhãn (chiếm tỷ lệ 34,5\%).

\section{BÀN LUẬN}

Với tốc độ tăng trưởng dự báo hàng năm là $6 \%$ đến năm 2020, ngành công nghiệp nước giải khát ở Việt Nam nằm trong số các ngành công nghiệp hàng tiêu dùng tăng trưởng nhanh nhất. Tiêu thụ đồ uống ước tính đạt 81,6 tỷ lít trong năm 2016 với triển vọng đạt 109 tỷ lít vào năm 2020 [7], qua khảo sát 58 mẫu đồ uống không cồn mang thương hiệu khác nhau đang được kinh doanh trên địa bàn tỉnh Bình Dương năm 2018, kết quả cho thấy:

Có khoảng $40 \%$ mẫu đồ uống trong khảo sát có chứa ga. Kết quả này phù hợp với nghiên cứu tại Việt Nam và Philipines năm 2015, Việt Nam là một trong những quốc gia có tốc độ tăng trưởng nhanh chóng về doanh thu cho nước ngọt có ga [10]. Nhóm đồ uống hương liệu được chiếm tỷ lệ cao nhất $(29,3 \%)$; nhóm đồ uống nước trái cây và trà, cà phê, ca cao chiếm tỷ lệ lần lượt là $27,6 \%$ và $20,7 \%$ (Bảng 1 ). Kết quả này phù hợp với thống kê tiêu thụ đồ uống tại Việt Nam năm 2016 (với 24,4\% đồ uống năng lượng; 23,05\% nước soda; 42,36\% nước trái cây; $42,34 \%$ trà) [11]. Lý giải hợp lý cho điều này vì đồ uống hương liệu đa dạng mẫu mã và sản phẩm, có giá thành thấp, đáp ứng được nhu cầu vị giác của người tiêu dùng, khiến việc tiêu thụ đồ uống hương liệu phổ biến và được các nhà buôn bán chọn lựa trong việc kinh doanh đồ uống không cồn. Trong nghiên cứu này, có $89,7 \%$ đồ uống được sản xuất trong nước. Mặc dù các sản phẩm đồ uống được bày bán trong siêu thị được sản xuất tại Việt Nam, tuy nhiên, một thực tế còn tồn tại là đa phần các công ty sản xuất nước giải khát lớn đều là các công ty nhượng quyền của nước ngoài hoặc có chi nhánh sản xuất tại Việt Nam (Bảng 1). Điều này cho thấy dù ưu tiên dùng hàng Việt, nhưng vẫn có sự chọn lựa giữa các sản phẩm được sản xuất bởi các công ty có danh tiếng so với những công ty nhỏ lẻ trong nước.

Nước ngọt thường chứa từ $1 \%$ đến $12 \%$ đường trong thành phần [9]. Trong nghiên cứu này, có $57 / 58$ sản phẩm khai báo có sử dụng đường trong thành phần sản phẩm, trong đó đường mía được sử dụng chủ yếu (91,2\%). Trong số các chất làm ngọt nhân tạo được khai báo sử dụng thì 
ACK được sử dụng phổ biến nhất (50,9\%), các lại chất tạo ngọt khác chiếm tỷ lệ từ 3,5 đến $21 \%$ (Biểu đồ 1 ). Kết quả này cho thấy ngoài đường mía chất làm ngọt $\mathrm{ACK}$ đang được sử dụng phổ biến trong các sản phẩm nước giải khát không cồn đang được kinh doanh trên địa bàn tỉnh Bình Dương. ACK có độ ngọt gấp 200 lần so với sucrose, ổn định nhiệt và $\mathrm{pH}$, và hòa tan tự do trong nước. FDA, FAO / WHO, JECFA, và Ủy ban khoa học về thực phẩm của Liên minh Châu Âu (SCF) đã kết luận rằng $\mathrm{ACK}$ là an toàn để sử dụng trong thực phẩm và đồ uống [9]. Đây là lý do ACK được các doanh nghiệp sản xuất đồ uống không cồn lựa chọn sử dụng phổ biến.

Chất ngọt tổng hợp là phụ gia thực phẩm không phải là đường có nguồn gốc tự nhiên được sử dụng với mục đích tạo vị ngọt cho thực phẩm. Tại Việt Nam, chỉ có quy định hàm lượng từng chất được phép sử dụng trong từng nhóm sản phẩm nhất định, chưa có quy định cụ thể về số lượng chất tạo ngọt dùng trong sản xuất thực phẩm. Trong nghiên cứu có trên $45 \%$ các sản phẩm sử dụng từ 02 chất làm ngọt trở lên trong sản phẩm nước giải khát không cồn (Biểu đồ 2 ). Điều này cho thấy các doanh nghiệp có xu hướng hạn chế việc lạm dụng chất ngọt tổng hợp trong sản xuất đồ uống không cồn.

Có $50 \%$ các sản phẩm đồ uống có chứa $\mathrm{ACK}$ trong sản phẩm. Hàm lượng $\mathrm{ACK}$ trung bình là $175,2 \pm 113,4 \mathrm{mg} / \mathrm{L}$, cao nhất là $481,7 \mathrm{mg} / \mathrm{L}$, thấp nhất là $11,9 \mathrm{mg} / \mathrm{L}$. Trong sản phầm đồ uống có gas, hàm lượng $\mathrm{ACK}$ là $119,5 \pm 110,25 \mathrm{mg} / \mathrm{L}$. Trong nghiên cứu này, hàm lượng $\mathrm{ACK}$ trung bình cao nhất trong nhóm đồ uống hương liệu $(208,2 \pm 127,9 \mathrm{mg} / \mathrm{L})$; thấp nhất trong nhóm nước trái cây: $99 \pm 92,8 \mathrm{mg} / \mathrm{L}$ (Hình 2 ). Kết quả này cao hơn so với nghiên cứu của Janina S.G. D năm 2013 (hàm lượng $\mathrm{ACK}$ là $82 \pm 64 \mathrm{mg} / \mathrm{L}$, dao động $1,59-283,7 \mathrm{mg} / \mathrm{L}$, trong đó nước giải khát truyền thống là $38 \mathrm{mg} / \mathrm{L}$, dao động $18,2-178,5 \mathrm{mg} / \mathrm{L}$, đồ uống năng lượng $66,3 \mathrm{mg} / \mathrm{L}$, dao động $0-198,8 \mathrm{mg} / \mathrm{L}$ ) [8] và nghiên cứu của Do. $\mathrm{B}$ tại Hàn Quốc năm 2017 (hàm lượng trung bình của $\mathrm{ACK}$ trong nước trái cây và rau rủ là $36,5 \mathrm{mg} / \mathrm{L}$; trong nước giải khát có gas là 111,8 $\mathrm{mg} / \mathrm{L}$; đồ uống hương vị sữa chua là $49,4 \mathrm{mg} / \mathrm{L}$ ) [4]. Sự khác biệt này có thể là do công thức sản xuất thực phẩm của các doanh nghiệp tại mỗi quốc gia khác nhau và hàm lượng sử dụng $\mathrm{ACK}$ trong sản xuất thực phẩm theo pháp luật tại mỗi quốc gia có sự khác biệt. Tuy nhiên, các doanh nghiệp đều tuân thủ quy định về hàm lượng $\mathrm{ACK}$ sử dụng trong sản xuất, đối chiếu với hàm lượng ACK theo quy định thì các sản phẩm đều đạt (Bảng 6).

Theo quy định ghi nhãn tại Việt Nam việc ghi thành phần phải ghi tên nguyên liệu kể cả chất phụ gia dùng để sản xuất ra hàng hóa và tồn tại trong thành phẩm kể cả trường hợp hình thức nguyên liệu đã bị thay đổi, việc trên nhãn thực phẩm khai báo thông tin không đúng sẽ bị xử phạt theo quy định [3]. Trong nghiên cứu này mặc dù xét nghiệm có chứa $\mathrm{ACK}$ trong sản phẩm, tuy nhiên chỉ có 10 trong số 29 sản phẩm có khai báo sử dụng $\mathrm{ACK}$ trên nhãn (chiếm tỷ lệ 34,5\%). Điều này có thể là do người tiêu dùng Việt Nam thường không thích dùng sản phẩm có sử dụng đường hóa học vì có thể có ảnh hưởng đến sức khỏe nên doanh nghiệp đã cố tình không khai báo $\mathrm{ACK}$ trên nhãn sản phẩm, lừa dối người tiêu dùng và gây khó khăn cho công tác quản lý chất lượng sản phẩm. Từ đây, người nghiên cứu đề xuất cần có những biện pháp xử lý nghiêm đối với những doanh nghiệp cố tình không khai báo hoặc khai báo không đúng sự thật những nguyên liệu dùng trong sản xuất thực phẩm. Từ đó giúp người tiêu dùng có những lựa chọn thực phẩm phù hợp góp phần bảo vệ sức khỏe bản thân và gia đình.

\section{KẾT LUẬN}

Có $50 \%$ các sản phẩm đồ uống có đường đang kinh doanh tại tỉnh Bình Dương có chứa $\mathrm{ACK}$ trong sản phẩm. Hàm lượng $\mathrm{ACK}$ trung bình là $175,2 \pm 113,4 \mathrm{mg} / \mathrm{L}$, cao nhất là $481,7 \mathrm{mg} / \mathrm{L}$, thấp nhất là $11,85 \mathrm{mg} / \mathrm{L}$; hàm lượng $\mathrm{ACK}$ trung bình cao nhất trong nhóm sản phầm đồ uống hương liệu $(208,2 \pm 127,9)$; thấp nhất trong nhóm nước trái cây $(99 \pm 92,8)$. Có $65,5 \%$ sản phẩm 
có sử dụng ACK trong thành phần của sản phẩm nhưng không khai báo trên nhãn cho người tiêu dùng và cơ quan quản lý được biết.

\section{KIẾN NGHI!}

Cần tăng cường công tác kiểm tra, giám sát các sản phẩm đồ uống có đường trên được sản xuất kinh doanh trên địa bàn tỉnh Bình Dương;

Xử lý nghiêm đối với những doanh nghiệp có sử dụng ACK nhưng không khai báo trên nhãn;

Cần có quy định giới hạn rõ ràng, cụ thể về sử dụng số lượng chất làm ngọt được phép sử dụng trong một thực phẩm.

\section{TÀI LIỆ THAM KHẢO}

1. Bộ Y tế (2015) Văn bản hợp nhất số 02/VBNH-BYT ngày 15 tháng 6 năm 2015 về hướng dẫn việc quản lý phụ gia thực phẩm.

2. Chính phủ (2017) Nghị định số 43/2017/NĐ-CP ngày 14 tháng 4 năm 2017 về nhãn hàng hóa.

3. Chính phủ (2018) "Nghị định 115/2018/NĐ-CP ngày 04 tháng 9 năm 2018 Quy định xử phạt hành chính về an toàn thực phẩm".

4. Do. B. Lee. Y., Lee. G., Lim. H. S., Yun. S. S., Kwon. H. (2017), "Simultaneous determination of sodium saccharin, aspartame, acesulfame-K and sucralose in food consumed in Korea using high-performance liquid chromatography and evaporative light-scattering detection", Food Addit Contam Part A Chem Anal Control Expo Risk Assess, 34 (5), 666-677.

5. Chi. L. Bian. X., Gao. B., Tu. P., Ru. H., Lu. K. (2017), "The artificial sweetener acesulfame potassium affects the gut microbiome and body weight gain in CD-1 mice", PLoS One, 12 (6), e0178426.

6. Wang. R. Cong. W. N., Cai. H., Daimon. C. M., Scheibye-Knudsen. M., Bohr. V. A., et al. (2013), "Long-term artificial sweetener acesulfame potassium treatment alters neurometabolic functions in C57BL/6J mice", PLoS One, 8 (8), e70257.

7. https://evbn.org/vietnam-beverage-industry-report/ EVBN. (2018) VIETNAM BEVERAGE INDUSTRY REPORT, accessed on 04 September.

8. Janina S.G. D., Angelina P., Celeste M. L. (2013), "Risk assessment of additives through soft drinks and nectars consumption on Portuguese population: A 2010 survey", Food and Chemical Toxicology, 62 (2013), pp. 548 - 553.

9. Containers Kregiel. D. (2015), "Health safety of soft drinks: contents, and microorganisms", Biomed Res Int, 2015, 128697.

10. Labonte. R. Schram. A., Baker. P., Friel. S., Reeves. A., Stuckler. D. (2015), "The role of trade and investment liberalization in the sugar-sweetened carbonated beverages market: a natural experiment contrasting Vietnam and the Philippines", Global Health, 11, 41.

11. The Statistics Portal (2016) Vietnam: Which of the following beverages do you regularly consumer accessed on 04 September 2018. 


\section{Summary}

ACESULFAME K IN ALCOHOL-FREE BEVERAGES IN BINH DUONG IN 2018

AND THE DECLARATION OF ACESULFAME K CONTENT ON LABELS

Nguyen Van Dat, Tran Minh Hoang, Nguyen Thi Thanh Tuyen, Nguyen Thanh Truc

Binh Duong Provincial Department of Food Safety and Hygiene

Background: Acesulfame-K (ACK) is one of the artificial sweeters in modern diet with low calories content. However, toxicity data of ACK has not yet been studied adequately. The overuse of ACK in food manufacturing is considered a long-term issue for comsumers' health.

Objectives: The aim is to determine ACK contents in alcohol-free beverages and the percentage of enterprises that comply with the ACK declaration on labels of the products sold in Binh Duong province in 2018.

Method: A cross-sectional study was conducted in 58 alcohol-free beverage samples with different brands sold in Binh Duong Province from July to October of 2018.

Results: The prevalence of alcohol-free beverages containing ACK, which were for sale in Binh Duong Province, was $50 \%$. The ACK contents varied from 11.85 to $481.7 \mathrm{mg} / \mathrm{L}$ with the average of $175.23 \pm 113.35 \mathrm{mg} / \mathrm{L}$. The highest average ACK content was found in aroma beverages $(208.24 \pm 127.89 \mathrm{mg} / \mathrm{L})$ and the lowest one was detected in fruit juices $(99.03 \pm$ $92.78 \mathrm{mg} / \mathrm{L}$ ). There were $65.5 \%$ of products containing ACK, nonetheless, ACK was not declared onthe label to consumers and regulatory agencies.

Keywords: Acesulfame K, alcohol-free beverage, food labeling, Binh Duong. 